\title{
A Conversion Disorder
}

\section{SARAH JACKSON}

But first, a few remarks about the text—or texts—-that follow: on the one hand, I offer fragments of a study of the glove in Virginia Woolf's 'Mrs Dalloway in Bond Street'; on the other, I tender a glimpse of something else_-perhaps a dream, a memory or a story. Together, these paired texts play out some of the connections between reading, writing and 'conversion disorder'. You might think of the essay as a gathering_ — of flowers, gloves, sisters, looking-glasses and ghosts—or you might think of it as a kind of 'disordering' — a turning, a returning, or a turning inside out of literature and psychoanalysis. Forgive me if the ways that these two different texts touch on each other isn't always clear, and forgive me if they touch too much.

She leaves in the dark, her husband and daughter still sleeping. Easing the front door closed behind her, she listens for the soft click. It is frosty out; her feet make dark smudges on the grass and by the time she reaches the railway station her ears are singing with the cold.

The Parkway squats beneath the power station at Ratcliffe, its forecourt anonymous and glossy. Gloria stands beneath the cooling towers and listens to the roar. She thinks of all the people across the country, all over the world, all the cats, all the trees, every blade of grass, all of them roaring. The towers contain it all as they open their huge mouths at the sky.

Gloria is not one for roaring. She is no trouble, except for the recent problem with her right hand. Standing on the platform, she finds that it has gone numb in the cold so she wriggles her fingers inside her woollen gloves until she can feel again: the tingling starts just as the train emerges from the darkness, as if she is receiving electric impulses along the track. 
She heads for the quiet coach, but already there are rows of bodies in dark suits. She finds an empty seat opposite a Japanese girl talking softly into her phone and a man in a long dark coat reading a newspaper in French. When she catches her eye, the girl smiles, as if they are sharing a secret, and Gloria has that feeling she sometimes gets.

The dark slowly lifts. The black gives way to violet and there is a splash of yellow to the east. She watches the passing farms and fields: the horses with frost on their beards and ears full of longing. She wraps herself up in her navy coat and smiles at that jolt in her bones when the train changes track. Then she checks her bag. She has a brand new green notebook, three sharpened HB pencils and a copy of A Haunted House: The Complete Shorter Fiction by Virginia Woolf. She rearranges her wallet, phone and keys in the front pocket of her rucksack. Her husband's rucksack. A loan, for the day. She will, after all, be returning. Gloria also has a cheese and cucumber sandwich, a bottle of still water and seven undergraduate essays on 'The Turn of the Screw'. And her A-Z street-finder, which she tells herself she must look at furtively, in the toilets, so that nobody will realise when she's lost.

The journey down to London is like turning up the sound. The people get louder and clearer and start to suck pastries and slurp skinny lattes. She begins to pick out snippets of conversation amidst the roar. A girl several seats behind her starts shouting into her phone about the damned florist. Gloria is tempted to turn around and glare.

At Leicester, she retrieves her notebook and pencil and places them on the table. She wants to write but her fingertips are still cold. For months after her daughter was born, she could barely lift a pen. She'd thought of it a good deal, ideas for books piling up on her like bricks. But things back then were ragged and thoughts couldn't be ironed out. Finishing anything seemed impossible. It's different now. She can go all the way to London and it doesn't matter if she doesn't write a thing.

Gloria unzips the front pocket of her bag and reaches for Woolf, opening it at 'Mrs Dalloway in Bond Street'. She settles into herself. 'Mrs Dalloway said she would buy the gloves 
herself.' She wants the French ones, with pearl buttons, Gloria reads, but—-the shop-girl saysthey've never been very reliable since the war. Scribbled slantwise in the margin, Gloria has written: 'remember: the flowering of the day'. Well, Gloria assumes she wrote it—she can't actually remember doing it, or why she might have done it. It's been like that for a while. Sometimes, she finds notes to herself, tucked into a recipe book. She didn't realise at first, but now when people talk to her of anniversaries or holidays or films, she understands that there are pages of her memory missing. She knows, of course, that the months have passed and the story has unfolded. Her daughter has grown taller and fatter and now has glorious, gappy teeth.

Sometimes, Gloria is sad when she thinks of all the books she has forgotten. Imagine forgetting a book you'd just read! Her husband reminds her that this means she'll get the pleasure of reading it for the first time all over again.

She runs her finger down the crease of the page and it is as if her hand belongs to someone else. Yet she is pleased at the paper's quality. Gloria smiles to herself. She is noticing things again. Small things: a feather; the taste of basil; yesterday, a hot air balloon! They'd watched it inch across the sky from the back bedroom window, its slogan-'Global Connections'-gradually revolving. She'd carried her daughter to the front of the house and then through the door and down the path in her pyjamas. But her daughter had cried when it disappeared from sight and Gloria had found herself apologising again. She glances out at the sky now, which is brightening, although paler at the horizon where it meets a line of brown and yellow trees.

Gloria has been back at work for six months and, apart from her hand, she is managing fine. She is methodical. She handles awkward emails with finesse. Important messages have little red flags. Some days she dreams of little red flags, like a golf course. Last night she woke up afraid that there was somebody else in the room. Her hand was numb again. It lay there between them like a stranger, naked and embarrassed. She found she had to pick up her own arm with 
her left hand. It was heavier than she expected and she was afraid of dropping it, of it falling out of bed and landing on the carpet with a thud.

And then the train pulls into St Pancras and Gloria thinks perhaps she has nodded off. She has to hurry to get her things and London, as always, clatters around her head. She holds her bag against her chest as she is jostled down the platform, posted through the ticket machine, and it is then, with an awful lurch, that she realises that she has left Virginia Woolf on the train.

'Mrs Dalloway in Bond Street', the short story that Virginia Woolf would later develop into her novel, opens: 'Mrs Dalloway said she would buy the gloves herself'. ${ }^{1}$ Clarissa Dalloway, it emerges, is in dire need of a decent, well-fitting pair of gloves. Entering the shop, she adopts a 'charming voice': “"White gloves," she said. "Above the elbow," and she looked straight into the shop-woman's face' (150). Her current pair, she explains, “'really don't fit"' (150). Perhaps, Clarissa says, it's her rings, but according to the shop-girl her hands are unusually slender. So begins the struggle: to find a pair of gloves that fit: 'they were all too large-always too large at the wrist' (151). In his essay on 'Accessorizing Clarissa', Mark Gaipa insists that the size of this glove is crucial. He points out that Mrs Dalloway's size - 'five and a quarter' (153) - is smaller than the industry standard, which 'usually ran, at quarter-inch sizes, from 5.5 to 8 inches'. ${ }^{2}$ But, Gaipa goes on to point out, Clarissa's gloves are not only baggy about the wrist, they are also too short: 'when measured against other women,' he notes, 'Clarissa seems to be uniquely-proportioned, with her arms (as it were) too long for her hands, and her hands to slender for her arms' (26). When another customer enters the shop, whom Mrs Dalloway eventually recognises as Miss Anstruther, it transpires that she, too, is looking for a glove that fits: 'And then the other customer took a glove, tugged it, and it split' (152). The shopwoman claims it is "a fault of the skin"' (152) and immediately produces an alternative. Finding a glove that fits-the body and the occasion-is clearly difficult to pull off. 
The size of the glove isn't all that matters. In fact, Clarissa is acutely aware of the glove's role as a signifier of class and recalls, 'A lady is known by her gloves and her shoes, old Uncle William used to say' (151). Naturally, she requires gloves that befit her status and the occasion, and the pair she chooses, as Gaipa points out, are white, close-fitting and expensive, thus rendering her hands unable to contribute to any productive labour. ${ }^{3}$ In their discussion of the representation of the glove in Renaissance art and literature, Peter Stallybrass and Ann Rosalind Jones observe that while gloves have long had the practical function of protecting hands from the elements and from hard labour, 'the gloves of aristocrats and gentry-male and female alike-usually operated to display hands to which such labor was alien'. ${ }^{4}$ In other words, gloves are as much a symbol of one's distance from work as an attempt to protect one's hands from such work. The gloved hand, after all, is often disabled. Stallybrass and Jones observe:

The function of these gloves - for both men and women-was to occupy the hands in the manu-facture of the immaterial. They thus materialize a paradox: they draw attention to the hands while making the hands useless, or useful only for putting on or taking off a glove, or for holding gloves or handkerchiefs or fans or flowers. (118)

Building on this, however, we might also consider the ways that the hand has been privileged in Western philosophy and culture. It has been read as a sign of our intelligence since Aristotle; it is, for Heidegger, a mark of the human, and signifies, Steven Connor remarks, 'the body's possibility'. ${ }^{5}$ The glove, then, deals a double-hander; while it protects the human hand, it risks rendering that hand useless, robbing it of its individuality and agency. Clarissa's glove-buying expedition is thus bound up with her personal and social identity, as well as another hand in her affairs.

Clarissa's glove, we assume, operates as one of a pair. It is interesting to note, however, that Woolf's description of her purchase frequently features a single hand or glove. When Clarissa tries the French glove for size, for instance, she 'looked at her arm in the looking-glass. The glove hardly 
came to the elbow' (151). Later, we are presented with her arm 'flecked with powder', and when she makes a decision regarding her purchase, she takes 'the glove in her hand', rather than the pair (152). We might question Woolf's focus on single hands, arms and gloves. Drawing on Jacques Derrida's discussion of 'the stake of the pair' in The Truth in Painting, where he stresses that a pair of shoes is 'more easily treated as a utility than a single shoe or two shoes which aren't a pair', Jones and Stallybrass point out that a pair 'normalises', perhaps even sanitises, the glove's function. ${ }^{6}$ Derrida argues that by giving them a function, the pair resists 'the "fetishizing" movement', or the possibility of 'a so-called perverse usage'. ' This pair, however, is always threatened by the possibility of its own unpairing, a possibility inherent in the common expression, 'on the one hand / on the other hand', which Stallybrass and Jones note 'unpairs the human body, setting the right hand against the left, the left against the right' ${ }^{8}$ Recalling a 'tactile presence or gaping hollow', they claim that when the single glove is 'released from the "utility" of the pair' (141), it 'becomes a vagina' (127). Pointing out that the 'unpairing of the hands is staged again and again in Renaissance portraits where the sitter is posed with one glove on, one off' (119), they turn to Antonio Mor's painting of Anne of Austria (1570) and note her one gloved and one bare hand. The gloved hand, they observe, 'holds the other glove like a third, crushed hand' (121). 'No longer structured by flesh and bone, collapsed in on itself, the fingers flattened and curling at the ends' (123), the empty glove is always 'haunted by its absent other' (132). Feminine, unpaired, hollow and ghostly, perhaps the single glove in 'Mrs Dalloway in Bond Street' also signifies otherwise.

When the escalator churns her out and Gloria takes her first step into the rattle and blast of King's Cross, it is into a crisp blue day. A glorious day, she thinks, shaking off the chaos of National Rail. A day for aeroplane trails and for holding cups of takeaway black coffee with two 
hands and blowing. For so long, she thought she would never feel this way again. And now, when it slips up on her, it is like the sun full on her face.

Dodging the taxi rank, she walks past the coffee shops, through the portico and across the piazza. She passes the huge bronze, but stumbles when she notices a child's green mitten left on a bench. She thinks of her daughter and hopes that today she'll agree to her warm winter coat. She checks her mobile, thumbing a quick message home: Don't forget the flowers. Thank you for everything. She hears a hollow ringing sound and looks up to see the back of an ambulance turn down Judd Street.

The guards at the entrance to the library ask her to unzip her rucksack and they finger through it. She is afraid of what they might find, and when they nod to let her pass, she stumbles as if she wants to tell them to look again. As she makes her way to the cloakroom, she thinks she hears some sort of siren.

The library has an underground feel. She locates the lockers, retrieving a pencil and notebook and placing them inside the complimentary clear plastic bag. All around her, people bustle and swear. Gloria stands, but without all her belongings, she feels as if she is walking from the changing rooms to the swimming pool without a towel. She pulls her cardigan around her and puts her phone and purse in the bag too, in case there's anything she wants to photocopy. And with a final sigh, she bundles in the seven undergraduate essays.

She heads to the reading room on level 2. She has ordered her research materials already and soon retrieves her small, sensible pile of books. Choosing a seat towards the back of the room, she looks around. Almost everyone has some sort of electronic device for writing. She'd like to think that's why she feels so paralysed—she needs some sort of prosthesis. She glances back down at her pencil. No excuses, she says sternly to herself.

Putting the marking to one side, she settles with her books and papers. Gloria has requested an article on cheiroarthropathy and something on dead finger, but she starts with Mitchell and Black's Freud and Beyond, where she hopes to track down the origins of the term 
'glove anaesthesia'. Her own numbness is limited to her right hand and fingers. Technically, that's impossible, she knows, because her nerves aren't severed at her wrist. It comes and goes. Mostly, she gets by, except when she tries to write. She resorts to stabbing things out with her left index finger on a keypad. Her husband insists it is repetitive strain injury and she needs nothing short of a rest, but she's been reading up on conversion disorder. She's even asked the doctor. The doctor had warm brown skin and motherly hips, and for a moment, Gloria wanted the doctor to- - she didn't know.

An elegant white-haired man puts some books on the desk beside her and vanishes. Gloria sneaks a look. Glas by Jacques Derrida. She's about to investigate further when he

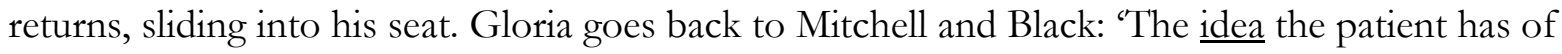
his hand is central to the functional disability. It is not the nerves themselves that are damaged; something is disordered in the patient's thoughts, thoughts about his_-'. The man exhales audibly and pushes back his chair. He nods at her and Gloria feels herself flush.

When she is sure he has gone, she leans in: 'And glas, a profusion of names sleeps in those letters.' Gloria turns the page: '... they are almost fake gloves, kitchen gloves, the "dishgloves" with which, at the close of the ceremony, the strangling of Madame is mimed, and-'. There, the page ends. Almost unreadable. The sense of so many words reaching in different directions like spreading roots. But isn't that what counts? She is suddenly deflated. She looks up and sees everyone else hard at work. Busy, obedient minds. Some people don't even appear to be taking notes.

Gloria sighs. All these books. Imagine all the books in the library lined up, all those sentences stretched and clamouring: the letters pouring through the city streets, along the underground, spreading out across the parks like a monstrous hand. It's in the fingerprints, written into the earth's core, and all around her now ... words!

She gags. Her hand holds the pencil like the claw of some ugly, awkward bird. Her muscles seize and her little finger doubles up as if it has a life of its own. She grabs her bag with 
her left hand and rushes from the room. The man is returning to his desk and he cries out after her. 'Excuse me, excuse me_-'. But Gloria has gone, running down the stairs and past the chirruping café, and the clever postgraduates, and the grandmothers, and the people prattling to their computers and at their telephones, and down past the books in their glass cases and across the glossy floor, and out, and out through the revolving glass doors.

Gloria stands there, looking out at London. She takes a deep breath. If you listen, behind the talking, you can hear the city breathing. If you listen, you can hear all those words crawling across the floor.

The famous photograph of the social worker, philanthropist and founder of the Jüdischer Frauenbund (League of Jewish Women), Bertha Pappenheim (1860-1936), bears the date ' 1882 ' . ${ }^{9}$ In this image, Pappenheim-a healthy-looking, upper-class young woman-is dressed in a riding habit, complete with hat, whip and gloves. The whip she holds in her right hand, but rather than wearing the gloves, or even wearing one glove and holding the other, Pappenheim wears neither; instead, they are both held loosely in her left hand. The fingertips point down, but because the pair are held together, it seems that the gloves themselves are holding hands. In fact, replicating and repeating the position of Pappenheim's 'real' hand, the gloves function as a strange prosthesis or artificial double-handed limb, extending her own reach. These gloves can, of course, be read in a number of ways - the empty hollow suggesting an 'absent other' or, in contrast to the phallic whip, signifying an alternative feminine sexuality. However, the pairing has additional resonance when we take into account the fact that Pappenheim - a highly-educated woman born into a distinguished Jewish family - was also the true identity of Josef Breuer's famous patient, Anna O. In a sense, then, the gloves point to Pappenheim's 'double'. Moreover, one of the conditions from which Anna O. is reported to have suffered is 'glove anaesthesia', a term first used by Jean-Martin Charcot to describe 
the hysterical paralysis of the hand. ${ }^{10}$ The empty gloves that Pappenheim holds in her left hand both allude to and disrupt the identity and diagnosis given to her by Breuer.

Presenting herself for treatment in 1880 at the age of twenty-one, Anna O. actually suffered from a number of hysterical symptoms, which included unexplained paralysis, primarily in the right side of her body, visual impairments including hallucinations, aphasia and a phantom pregnancy. ${ }^{11}$ Breuer describes Anna's illness as falling into four separate phases: latent incubation from the middle to the end of 1880; the manifest illness; a period of somnambulism; followed by a gradual recovery from her symptoms and discharge in June 1882 (PFL 3: 74-5). Breuer reports that at the onset of her illness and while staying in the country, Anna helped care for her father who was suffering from a sub-pleural abscess, from which he later died (PFL 3: 92). Here, she experienced a trauma that became the source of her own psychosomatic disorder and, in particular, forms the origin of the paralysis of her right hand. One night, Breuer writes, she awoke in a state of 'great anxiety' about her father, who had developed a high fever. He explains:

(...) Anna was sitting at the bedside with her right arm over the back of her chair. She fell into a waking dream and saw a black snake coming towards the sick man from the wall to bite him. (...) She tried to keep the snake off, but it was as though she was paralysed. Her right arm, over the back of the chair, had gone to sleep and had become anaesthetic and paretic; and when she looked at it the fingers turned into little snakes with death's heads (the nails). (PFL 3: 93)

Breuer suggests that his patient may have 'tried to use her paralysed right arm to drive off the snake and that its anaesthesia and paralysis had consequently become associated with the hallucination of the snake' (PFL 3: 93). The following day, during an outdoor game near a bush, she mistook a bent branch for a snake; this 'revived her hallucination of the snake, and simultaneously her right arm 
became rigidly extended' (PFL 3: 93). According to Breuer, it was only when she finally retrieved this memory that her paralysis was cured.

Anna O.'s condition is an example of what Freud describes as 'conversion disorder': 'the translation of purely psychical excitation into physical terms' ${ }^{12}$ Freud first used the term 'conversion' in a paper on defence neuropsychoses published in 1894 to refer to the process whereby an 'incompatible idea is rendered innocuous by the sum of excitation being transformed into something somatic' ${ }^{13}$ In Studies in Hysteria he explains that when an unacceptable thought or feeling is repressed, it persists as a 'memory trace' which is 'converted' to a bodily expression (PFL 3: 370-1). For Freud, the hysterical symptom in question is usually related to some degree to the original traumatic experience, which means that the site of the physical symptom often coincides with the original site of injury or distress, although a period of incubation may intervene before the symptom arises. ${ }^{14}$ Lilian Furst points out that when emotions are converted into symptoms, a process of translation takes place whereby the individual's psychological distress is 'simultaneously masked and manifested in a nonverbal style of communication' ${ }^{15}$ The emotion, therefore, is at the same time hidden and exposed, expressed and unspoken. Furst describes this as a 'tension between knowing and not knowing, concealment and revelation' (68). Curing conversion thus involves the revelation of known secrets. In order to recover the original trauma-to 'tell the secret' - the repressed emotion must be retrieved, realised and spoken. However, Furst also points out that a 'further conversion' must take place when we read psychosomatic symptoms in literary texts: 'So in the literary portrayal of conversion disorders, a dual translation occurs: from the fictional character's mind into his/her body and also into the linguistic medium of the text. ${ }^{16}$ Reading, for her, is a double process of conversion, involving its own kind of disorder. 
After some trouble with an Oyster card, Gloria finds herself at the Victoria and Albert. Her father used to bring her here as a child. His favourite section was the Middle East. They'd peer at objects and her father would push his glasses back up his nose and sniff. But today she finds herself climbing the marble steps to the British Galleries on the second floor. She almost knocks into the display of delphiniums on a cherry wood stand by the door.

It's a relief to enter the gallery, where objects hum quietly in their glass crypts. She's not looking for anything in particular, just winding around display cases, in and out of light and shadow and through the murmur and swell of voices. She'd pulled herself together after the fiasco at the library. Realised that what she really needed was to get out. Stop worrying. And she has such fond memories of her trips to London with her father.

A woman passes, pausing to press her camera to the glass. Curious, Gloria leans in to see what she photographed —an engraved silver watch—but as she steps back, there is a tilting of perspectives. She faces not the watch but another face, her own owl-eyed stare. And yet beyond that, there is another face. Straight-nosed, lips pursed. She turns-

Case 3, shelf D3. There are two of them, dolls made of turned wood. Larger than you might think. Standing, they'd be around shin-high. They have pale foreheads and polished cheeks. Lord and Lady Clapham, she reads. Thought to belong to the Cockerell family in the late seventeenth century, descendants of Samuel Pepys. The small man has square shoulders and jointed legs, which are hinged at the thigh and the knee. His hands and face are gessoed. He wears a red coat buttoned over a waistcoat, with breeches and real silk stockings. Human hair has been nailed to his head. There are little leather shoes with brass buckles, and a felt hat. An idea rolls over inside her. Gloria's forehead is against the glass, but then there is an eruption as a gaggle of primary school children surge through the gallery and she steps back, sweating slightly.

When the noise has died down and she is sure that they have all gone, she turns back and kneels to read the label: 'Accessories such as the stockings, neckcloth and gloves are very valuable since very few items from this early period survive in museum collections.' Gloria takes 
a breath. That's it. The gloves are missing. White kid leather and hand-stitched with brown silk thread. They've gone. Gloves were required by etiquette. To appear without was considered a sign of illness or distress.

She stands too quickly, turns, and turns again. A gallery assistant walks in and on through to the next room without looking back. Gloria is suddenly afraid. She stumbles to a bench and waits for the giddiness to pass. The museum moves around her. The floors tilt. Outside, a pigeon slides across the sky.

And then there is a man in a long dark coat walking towards her, and there is a lady standing at the entrance door, her hand to her mouth. The man extends his arm but Gloria hauls herself up sharply, reaches for her plastic carrier and careers away, down the stairs. She reels around the statues and, without looking back, bolts for the tunnel under Exhibition Road. Running through the curved shaft, the grey tiles on the walls glint in the artificial light.

This reading of 'Mrs Dalloway in Bond Street' is haunted by another pair of gloves. Jean Genet's play

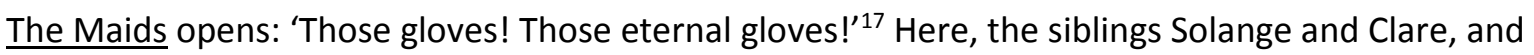
their ritual performance of the murder of their Madame, seems to mirror the motif of the (un)paired glove and the possibility of an absent other. Impersonating Madame-who Solange later describes 'strangled by the dish-gloves' (37) -Clare tells Solange to leave the gloves in the kitchen: 'You probably hope to seduce the milkman with them. No, no, don't lie; that won't get you anywhere! Hang them over the sink. When will you understand that this room is not to be sullied' (7). By focusing on a pair of gloves in their own double-act, the sisters emphasise the patterns of (un)doubling and (un)pairing that structure the story. ${ }^{18}$ Moreover, in his exploration of Genet's play in Glas, Jacques Derrida remarks that the maids themselves 'are gloves, the gloves of Madame'. ${ }^{19}$ They are in her grip but also under her skin. Derrida goes on to say, however, that 'between these 
pairs of gloves, flowers, only flowers, too many flowers' (48b). Here, he reminds us that in her opening speech, Clare is alternately spreading fanwise and folding a pair of rubber gloves 'in the form of a bouquet' (7).

In fact, the play is filled with bouquets. Even before the first word, the stage directions inform us that there are 'flowers in profusion' (7). Clare (as Madame) tells Solange (as Clare), 'You crush me with your attentions and your humbleness; you smother me with gladioli and mimosa (...) There are too many flowers' (8). When the 'real' Madame enters the scene, she remarks, 'Such horrible gladioli, such a sickly pink, and mimosa!' (24). Repeating Clare and Solange's earlier rehearsal, she echoes, 'There are times when you're so sweet that I simply can't stand it. It crushes me, stifles me!' (25). Derrida pursues the flower in Glas, a text that is constructed in terms of its own double columns. In one column, Derrida cites passages from Genet's work-Our Lady of the Flowers and Miracle of the Rose-which draw attention to the genitalia of flowers. In its 'sister' column, these flowers recur in his discussion of Hegel's religious imagery. The book-or rather, the 'antibook $^{20}$-is thus immersed in 'the language of flowers', which Henry Sussman notes 'flourish[es] on both sides of the Derrida guard-rail or fence' ${ }^{21}$ Crucially, then, observing the way that Derrida 'devotes his attention to the interweavings of stamens and styles' (281), Sussman argues that the recurrence of flowers in Glas is played out on a textual and a formal level: 'Flower arrangements', he says, 'assume the form of textual webworks and interlacings' (281)-a texture that is at the core of Glas, but the traces of which are also to be seen in the intertextual cross-pollination of works by Woolf, Bowen, Butts, Genet and others.

These flowers mean more than one thing. In Glas they signify fecundity; they have stamens and buds, they are symbols of arousal, and their cutting can be read as castration. The sexuality of flowers, then, is abundant. At the same time, however, as Sussman points out, flowers signify innocence, virginity, chastity (281). This leads Derrida to pronounce that 'the flower (which equals castration, phallus, and so on) "signifies" - again!' (47b). Or, he continues, 'at least overlaps virginity in general, the vagina, the clitoris, "feminine sexuality," matrilinear genealogy, the mother's seing, 
that is, the Immaculate Conception' (47b). The metaphor of the flower thus opens up to an alternative, feminine sexuality. But in order to perform this disruption, or to enact this reversal from the phallus to the vagina, Derrida suggests that it needs to be turned inside itself, like a glove: 'for alleged opposites to be equivalent to each other and reflect each other, the flower has to be turned inside out like a glove, and its style like a sheath [gaine]' (47b). What Alan Roughley describes as the 'flower/glove knot' thus functions as a model for the 'simultaneity and equivalence of the castration/phallus and the hymen/vagina' ${ }^{22}$ Its ability to signify again, its capacity to be 'reversed into the vagina' (47b), depends on the movement of eversion.

When she eventually arrives, it's gone rush hour but King's Cross is still swarming. Buses swing round corners, scattering pigeons. Taxi drivers honk their horns. Car alarms, police sirens, a guard's whistle: rings of sound. Every atom in the city seems to be calling out in protest at it all.

Gloria stands outside the station. Her ticket is a cheap advance and she's early. She can't face returning to the library, and St Pancras will be heaving so she ducks off Euston Road. There was a pub here, she's sure. Benches on the pavement. Once, one evening in June, they'd shared a bottle of cheap wine and a plate of spring rolls before getting the train home. Her husband, although he wasn't her husband then, said something about a friend they'd met but it was kinder than it sounded and they'd smiled. Years ago now. She thinks of her husband and daughter at home. Perhaps they are cooking. He will be chopping vegetables for soup and she will be standing on a chair trying to cut through a wooden carrot with a plastic knife.

Gloria is sure the pub is around this corner. She walks quickly, expecting to see the grimy bench chained to the floor, but there is just a dead-end and a storage warehouse with an old billboard advertising GlaxoSmithKline. Beneath it, a man in a dark coat stands with his hand on some railings, smoking. He fingers a shred of tobacco from his tongue and looks up. She double- 
backs and walks around the square again, trying one of the other side streets, but ends up back at the warehouse, only this time coming the other way. She almost falls over him. He opens and closes his mouth on his pipe, and she mutters an apology and runs.

She stumbles upon the steamed up windows of a café. It is bitterly cold so she slips inside, nodding at a couple drinking espressos and sharing the evening paper. She sees the headline: DEIRDRE IS DEAD. The letters warp and, for a moment, she thinks it says something else, and she wants to cry out: Who? Who? Who is dead? She has this sensation low in her body that she has missed something important and that it is already too late.

Gloria approaches the counter at the back of the cafe. A woman sits to one side, jiggling a pram with her foot while reading a blue book emblazoned How to Make an Impact. Gloria clears her throat and the waitress looks up. She orders a cup of tea and sits at the table by the window. It turns out a cup of tea in London costs $£ 2.95$ and really means a pot. It comes with a long teabag like a stocking filled with sand. The waitress brings the couple two plates of steaming moussaka and then returns to her seat. Gloria fishes her notebook out of the carrier bag, but the lines float in front of her face, so she stares out of the window at the orange glow of the street lights, which bulge and shrink in the dusk as if they are breathing.

The bell rings again and the door opens, letting in a great wash of cold air. When it closes, she looks up and sees that it is the man with white hair and a long dark coat. He sits at the bar at the back and the waitress gives him a drink, Gloria doesn't know what. She turns back to her work, but she has lost her pencil so puts her notes to one side and sits on her hands, which are glacial. She tries pinching her finger, but can't feel a thing.

Suddenly, Gloria cannot wait to be home. Her daughter will be having her bath. The windows will be closed against the cold and the blue towel will be warming on the radiator. Soon, they will begin the battle of brushing her teeth.

By the time she finishes her tea, it is tepid and bitter. She stands, ready to go. A hand touches her elbow. 
'Excuse me.' It is the waitress, who looks exhausted. 'Excuse me. I think you forgot these.' She holds out a pair of brown leather gloves.

'Oh, no,' Gloria replies. 'I’ve got mine here—or somewhere—anyway, they're not mine.'

'Yes,' the waitress insists. 'This man. He says you dropped them. They're for you.'

They both turn now to look at the stranger, but see only the space he has left behind, and it is then that they feel the rush of cold air and hear the bell jingle. It is a pure, sweet sound, ringing out through the night. The baby starts to whine.

'Take them,' the waitress says, thrusting the gloves at her.

Gloria thanks her and, leaving her bag on the floor and her notebook on the table, runs out into the dark, after the stranger. 'Wait! Please wait!' But he has gone and her voice rises up above the city and hangs there for a second before dissolving into the night.

It is, perhaps, ironic that the term 'conversion' is central to Woolf's novel, Mrs Dalloway, where it signifies yet again. ${ }^{23}$ Woolf describes one's sense of 'proportion' as having a sister-another sister'less smiling, more formidable' (85): 'Conversion is her name and she feasts on the wills of the weakly, loving to impress, to impose, adoring her own features stamped on the face of the populace' (85). Concealed 'under some plausible disguise; some venerable name; love, duty, self-sacrifice', Conversion 'offers help, but desires power' (85). Blanche Gelfant places the opposition between love and conversion at the heart of Mrs Dalloway. This 'polarity', she writes, 'gives Mrs. Dalloway the opportunity for the moral choices by which she creates her self', and forms the novel's basic structure and theme. ${ }^{24}$ Whereas love is considered 'creative', conversion is destructive, 'always indicating coercion', and is, for Gelfant, most crudely represented in the characterisation of Sir William Bradshaw. ${ }^{25}$ Clarissa, Gelfant insists, remains in defiance of conversion, although she admits that 'the intensity of her inner experience, so much at odds with her outer life, suggests that she is 
struggling against conversion not only in man and his institutions, but in life itself'. ${ }^{26}$ Conversion and its disorders, we might assume, are to be avoided. Yet responding to Jacques Derrida's account of conversion in 'Force and Signification' as a process of 'turn[ing] oneself toward the invisible interior of poetic freedom', there are clearly other methods of reading and writing conversion-or rather, there is a way of thinking about reading and writing as a kind of conversion disorder. ${ }^{27}$ And the return of the flower/glove knot in Woolf's work, I propose, offers us a compelling way of rethinking such disorder. Thus, in order to move forward, it is necessary to turn back or to begin again.

Woolf's story, written in 1922, begins, 'Mrs Dalloway said she would buy the gloves herself' (146). ${ }^{28}$ The novel, Mrs Dalloway, that the story would eventually become, however, opens, 'Mrs Dalloway said she would buy the flowers herself' (3). One word changes here: gloves and flowers are, henceforth, bound up in a textual knot. This shift has been interpreted by a number of critics, most notably in terms of the changes in Clarissa's characterisation, but few remark on the crossimplications of gloves and flowers. Mark Spilka for instance refers to a 'crucial' shift in Woolf's sympathy for Mrs Dalloway, which is signalled only by the 'slight shift from gloves to flowers' ${ }^{29}$ Far from being slight, this shift actually has important implications for Woolf's poetic act - her own experience of conversion.

For Woolf, the conversion from story to novel brings with it a linguistic flowering and in $\underline{\mathrm{Mrs}}$ Dalloway there are flowers everywhere: 'delphiniums, sweet peas, bunches of lilac; and carnations, masses of carnations. There were roses; there were irises' (11). What follows is a gathering of floral tributes: 'it was the moment between six and seven when every flower-roses, carnations, irises, lilac-glows; white, violet, red, deep orange; every flower seems to burn by itself, softly, purely in the misty beds' (11). Clarissa's 'floral raptures' ${ }^{30}$ seed and blossom through the pages of the novel, not only when Richard Dalloway brings Clarissa roses (100), nor when Elizabeth Dalloway is described as a 'hyacinth sheathed in glossy green' (104), but perhaps most overtly in Sally Seton's 'way with flowers': 
Sally went out, picked hollyhocks, dahlias-all sorts of flowers that had never been seen together-cut their heads off, and made them swim on the top of water in bowls. The effect was extraordinary-coming into dinner in the sunset. (Of course Aunt Helena thought it wicked to treat flowers like that.) (29)

By plucking off their heads, Sally makes clear that flowers, often read as symbols of life, sexuality and fertility, are also subject to castration. ${ }^{31}$ The flower/glove knot in Mrs Dalloway, then, dismantles différance. But Woolf's metaphor of flowering, as Bonnie Kime Scott notes, is also related to the 'seed-scape'. Examining Septimus Smith's apprehension of time-'the word "time" split its husk' (59) -Kime Scott notes that 'Woolf frequently uses figures of words as seeds' and that this 'suggests a compos[t]ing of the word in mud or water and encompasses the swelling and exploding into life of the germinating seed' ${ }^{32}$ She relates the seed metaphor to Derrida's concept of 'dissemination' 'seminal différance' or the seed scattered elsewhere. ${ }^{33}$ Playing on 'the fortuitous resemblance (...) of $\underline{\text { seme }}$ and semen', Derrida refers to 'an irreducible and generative multiplicity'. ${ }^{34}$ Endlessly repeated, Gayatri Chakravorty Spivak explains that this is a 'semination that is not insemination but dissemination, seed spilled in vain'; it is 'not an exact and controlled polysemy, but a proliferation of always different, always postponed meanings' ${ }^{35}$ It is at work, moreover, within the parts of individual words, and 'becomes pervasive in Glas, where the individual phonemes/graphemes constituting words are often evoked out into an independent dance'.$^{36}$ Traces of this proliferation, both within the word and throughout the text, I suggest, are also to be unearthed in Mrs Dalloway.

It is gone eleven when the train finally heaves into the Parkway. They have gritted the platform. Gloria searches her pockets for her ticket and finds only her keys and the gloves. The guard shouts and the doors start to slam and even now, she can't move. Standing beneath the cooling 
towers, she is so small. She cannot remember how often she has thought this. She looks up at the towers and feels the noise fall like rain on her face.

The bus drops her on Rufford Road and rattles away. The grim-faced driver remembered her, took kindly to her story. A light is on in the tall house at the corner, and as she passes, a dog barks. She sees another set of footprints on the grass and opens the gate to their front door.

She's misplaced her keys, of course, but her husband has left the door on the latch. She eases it open; they will both be sleeping. He has left the standard lamp in the corner on but it is covered with an old scarf which gives the room a blue-green tinge. She picks up a glass from the low table and walks into the kitchen. On the sideboard there is a bag of gladioli bulbs. Her husband and daughter are looking forward to Spring. Soon they will be able to start digging. Suddenly, Gloria wonders if she might join them.

Upstairs, she creeps into her daughter's room, where she is spread out on the bed like an open suitcase. She bends over, smells her, fresh as the earth. Next door, her husband is asleep with his thumb still between the pages of his book. Later, when she climbs in beside him, he will murmur and the book will fall to the floor. He will wake for a second-long enough to turn to her and ask her, briefly, how she got on.

First, though, Gloria climbs the stairs to the attic with the sound of London still ringing in her ears. The door handle creaks. She steps over the doll's house and the oil paintings piled against the wall, and tiptoes to the desk, making sure she doesn't scrape the chair on the floorboards. Carefully, she places the gloves on the shelf as if she is trying not to wake them. Those eternal gloves! she thinks, and remembers the man. Then she picks up a pen, rolls it between her fingers. It is not that there are no words; rather, there are too many and none of them are right. She arranges the sheaf of papers. She tries composing in her head.

A word. Even her own name. G. Gl. Gl. 
In The Maids, Madame believes the sisters are preparing her tomb as they gather gladioli for her funeral: 'And those flowers which are there for the very opposite of a celebration!'37 The death knell (glas) resounds, of course, throughout Derrida's work with every repetition of 'gl': gloves, gladioli, (looking-) glasses, glaives (swords). For Sussman, Glas sings this 'gl'; it 'pursues a meandering path, passing from one semantic field to another with unpredictability, impunity, speed, and seeming arbitrariness (that is, the arbitrariness is "always-already" installed in the language network itself)' ${ }^{38}$ Not mere word-play, this mark overturns traditional ideologies of sexuality and difference. Like the flower/glove knot, and swinging neither in the masculine nor the feminine, the 'gl' has, Derrida insists, 'no identity, sex, gender, makes no sense, is neither a definite whole nor a part detached from a whole': 'Gl remain(s) gl', he writes (119b-120b). Ringing with the 'mark' 'gl', Glas sings the reserves of language.

But there is also, I propose, a scattering of the 'gl' in Mrs Dalloway, which features its own death knell in the form of 'the bell [which] flooded the room with its melancholy wave; which receded, and gathered itself together to fall once more' (100). Embedded within the very idea of 'Englishness' that the novel adopts, we find the 'gl' in the 'glittering stars' (15), the 'gleaming lakes' (162), and the things that 'conglomerated there in the darkness' (20). Clarissa watches the cars 'gliding across Piccadilly' (15), and the buses, 'like garish caravans, glistening with red and yellow varnish' (114). And, as in The Maids, there are a proliferation looking- (and other) glasses $(31,77$, 113), which reflect characters who are 'glum, gloomy' (51) or 'glaring' (74). Miss Kilman, in particular, spreads the word: 'So she glared; so she glowered' (106). We encounter tangles, spangles, jingles, broken beer glasses, things that tingle and glitter and glow ... 'and so on into the flare and glare' (139). The flowering of the text, then, is the scattering of the ' $\mathrm{gl}$ ', and reading this dissemination both within and across texts offers us alternative ways of thinking about the idea of disorder. ${ }^{39}$ 
So we have turned from the glove to the flower to the ' $\mathrm{gl}$ ' and back. This has involved a series of digressions and diversions, which are at the heart of conversion. Furst points out that in his study of Dora, Freud describes conversion disorder in terms of both 'Verbrängung' (repression) and 'Verschiebung' (displacement). ${ }^{40}$ She continues: 'the German particle "Ver-" conveys the sense of something gone askew, pushed or shoved out of its proper place, as happens when the psyche speaks through the body'. ${ }^{41}$ Turning or going askew - a movement Nicholas Royle has termed 'veering' - is thus at the heart of the experience of conversion. Referring to its 'revolutionary potential', Royle writes:

Veering is a little word, but an investigation of its strange nature brings into consideration a rich freight of other words, including the many English words that entail turning, and perhaps especially those that relate to the Latin vertere, such as 'version', 'verse', 'vice versa', 'vertigo', 'versatility', 'converse', 'conversion', 'perverse', 'averse', 'reverse', 'inversion', 'diversion' and 'subversion. ${ }^{42}$

At its core, then, the experience of conversion is an experience of turning-a diversion that revolves around the possibility of disorder. This 'ver' echoes uncannily in Hélène Cixous's discussion of conversion in Hyperdream as she tries to understand her friend J.D.'s statement: 'Maybe I ought to convert'. ${ }^{43}$ Mourning his passing, she turns the sentence over and over until she finds what he calls 'the "Veridical"' (144). 'I laughed,' she says: 'It was his Ver coming back' (144), but it is an idea of the veridical that dislodges our conception of truth.

Derrida always comes back, of course, and the ways that his texts are 'handed on' remain central to this very conversion. ${ }^{44}$ His word 'conversion' signifies again; it is, for Cixous, a 'passkey' (144). And it is by turning the passkey in the lock that we can begin to approach poetic freedom and understand the strange eversion of literature and psychoanalysis, which will always be hand-inglove. 
It is as she is brushing her teeth that she thinks she hears it. A tinny sound followed by a faint scratch. She pauses, but it is nothing. She rinses her mouth and pulls the light cord. Passing the stairs to the top room she hears it again. A distant rasping. She climbs the stairs slowly and puts her ear to the door. And there it is again. The small sound of something moving. Like picking up a $\log$ and seeing the undergrowth flinch. She kneels down to look under the door.

Gloria senses his hand on her shoulder before she sees him. 'Love?' There is a crease between her husband's eyebrows. 'What's the matter?' he asks.

'I thought I heard something,' she says, straightening.

'It's so late.'

'I'm sorry. I was just coming and I thought—I thought I heard something.' She stalls. 'I mean, I thought maybe she was awake.'

'Dead to the world,' he says and then, with such tenderness: 'How was it?'

She is about to shake her head, but before she can stop him, his hand presses down on the handle and pushes open the door. He walks over to her desk. Gloria cannot move. The ringing gets louder but when she looks up he is smiling at her.

In his hand there is a page of writing.

He moves over to her and touches her chin. 'I told you it would come.'

'I've not even started,' she says, taking the paper from him and peering at the handwriting. She doesn't curl her 'g's like that.

'We'll go and feed the birds tomorrow. You can stay here and get on.' He kisses the curve of her neck.

She glances back at the page. 'Just five more minutes,' she says.

'Come on.' 
And this is the moment of conversion. Gloria separates from herself. She walks down the stairs and folds with relief into bed beside her husband and allows her eyes to close as she breathes in his warmth. But upstairs, there is another Gloria who remains in the attic and who is reaching for the single glove, which has fallen to the floor beneath the chair. So when Gloria turns in bed and takes her husband's hand, this other Gloria lifts the glove carefully because it still holds the shape of a limb. And as the Gloria downstairs drifts off to sleep, this double eases on the glove. And although Gloria is of course downstairs dreaming, there is a part of her-perhaps a part of us all—who is up here stretching out her fingers, feeling one hand inside another. Gloria is asleep, and yet she is up here too, and we are with her as she touches her own hand as if it belongs to someone else and then picks up a pencil. And perhaps we feel it too-that sense of being turned inside out, our fingers through our wrists, our throats through our mouths, the words coming. You are writing, Gloria says to herself. You are writing, she says to us, and yes, we are writing too, we are, and we are glad to feel the beat of our secret hearts, the blood blossoming in our veins, and then our hands, yes, all our hands, begin to move.

\section{$\underline{\text { Notes }}$}

${ }^{1}$ Virginia Woolf, 'Mrs Dalloway in Bond Street' [1923] in The Haunted House: The Complete Shorter Fiction (London, Vintage, 2003), 146-153 (146).

${ }^{2}$ Mark Gaipa, 'Accessorizing Clarissa: How Virginia Woolf Changes the Clothes and the Character of her Lady of Fashion', Modernist Cultures 4:1-2 (2009), 24-47 (26).

${ }^{3}$ Gaipa, 'Accessorizing Clarissa', 29.

${ }^{4}$ Peter Stallybrass and Ann Rosalind Jones, 'Fetishizing the Glove in Renaissance Europe', Critical Inquiry 28:1 (2001), 114-132 (118). 
${ }^{5}$ Aristotle, On the Parts of Animals, translated by James G. Lennox (Oxford, Oxford University Press, 2011), 99; Martin Heidegger, What is Called Thinking?, translated by J. Glenn Gray (New York, Harper \& Row, 1968), 16; Steven Connor, The Book of Skin (London, Reaktion Books, 2004), 140.

${ }^{6}$ Jacques Derrida, The Truth in Painting, translated by Geoffrey Bennington and lan McLeod (Chicago, Chicago University Press, 1987), 332, cited in Stallybrass and Jones, 'Fetishizing the Glove', 120.

${ }^{7}$ Derrida, The Truth in Painting, 332-3, cited in Stallybrass and Jones, 'Fetishizing the Glove', 120.

${ }^{8}$ Stallybrass and Jones, 'Fetishizing the Glove', 119.

${ }^{9}$ Photograph dated 1882 from the Sanatorium Bellevue archive in Switzerland.

${ }^{10}$ See Sander L. Gilman, 'The Image of the Hysteric' in Sander L. Gilman, Helen King, Roy Porter, G. S.

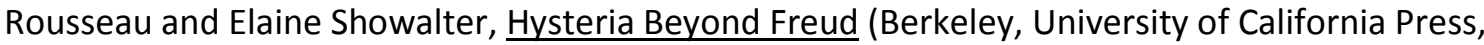
1993), 345-452 (391).

${ }^{11}$ Josef Breuer, 'Fräulein Anna O.' in Sigmund Freud and Josef Breuer, Studies on Hysteria: Penguin Freud Library (PFL), volume 3, translated by James and Alix Strachey (London, Penguin, 1991), 73102.

${ }^{12}$ Sigmund Freud, 'Fragment of an Analysis of a Case of Hysteria ("Dora")' [1905/1901] in PFL 8, 31164 (87).

${ }^{13}$ Sigmund Freud, 'The Neuro-Psychoses of Defence' [1894] in The Standard Edition of the Complete Psychological Works of Sigmund Freud [SE], volume 3, translated by James Strachey (London, Vintage, 2001), 43-69 (49), cited in Felix Deutsch and Elvin V. Semrad, 'Survey of Freud's Writings on The Conversion Symptom' in On the Mysterious Leap from the Mind to the Body, edited by Felix Deutsch (New York, International Universities Press, 1959), 27-46 (30). Deutsch and Semrad go on to point out that Freud always insisted that the concept of 'conversion' was 'arrived at jointly with Breuer, although he admitted he was responsible for the word "conversion" himself' (30). 
${ }^{14}$ Freud's account of the case of Frau Cäcilie M.'s facial neuralgia, which resulted from an insult that felt like a 'slap in the face', provides a useful example of this process of 'symbolisation'. See Freud, PFL 3, 249-254, and Deutsch and Semrad, 'Survey', 27-46.

${ }^{15}$ Lilian R. Furst, Idioms of Distress: Psychosomatic Disorders in Medical and Imaginative Literature (New York, State University of New York Press, 2002), 6.

${ }^{16}$ Furst, Idioms of Distress, 60.

${ }^{17}$ Jean Genet, The Maids [1953], translated by Bernard Frechtman (London, Faber \& Faber, 2009), 7.

${ }^{18}$ We should note the sisterly 'pairing' that features in The Maids in light of the uncanny prevalence of sisters in other narratives about gloves. See, for instance: Elizabeth Bowen, 'Hand in Glove' in $\underline{T h}$ Collected Stories (London, Vintage, 1999), 767-75; Mary Butts, 'With and Without Buttons' in The Complete Short Stories, edited by Bruce R. McPherson (New York, McPherson, 2014), 332-45; see also Sarah Jackson, Tactile Poetics: Touch and Contemporary Writing (Edinburgh, Edinburgh University Press, 2015), 140-149.

${ }^{19}$ Genet, The Maids, 7; Jacques Derrida, Glas [1974], translated by John P. Leavey, Jr. and Richard Rand (Lincoln, University of Nebraska Press, 1986), 48b.

20 J. P. Leavey, Jr., Glassary (Lincoln, University of Nebraska Press, 1986), 29c.

${ }^{21}$ Henry Sussman, 'Hegel, Glas, and the Broader Modernity' in Hegel after Derrida, edited by Stuart Barnett (London, Routledge, 1998), 260-293 (281, 282).

${ }^{22}$ Alan Roughley, Reading Derrida Reading Joyce (Gainesville, University Press of Florida, 1999), 50, 49.

${ }^{23}$ Virginia Woolf, Mrs Dalloway (Oxford, Oxford University Press, 2008).

${ }^{24}$ Blanche H. Gelfant, 'Love and Conversion in "Mrs. Dalloway"', Criticism: a Quarterly for Literature and the Arts 8:3 (1966), 229-245 (231).

${ }^{25}$ Gelfant, 'Love and Conversion', 232.

${ }^{26}$ Gelfant, 'Love and Conversion', 242-3. 
${ }^{27}$ Jacques Derrida, 'Force and Signification' in Writing and Difference [1967], translated by Alan Bass (London, Routledge, 2001), 1-35 (7).

${ }^{28}$ Mark Gaipa notes that in the original typescript, Woolf's story begins 'Mrs. Dalloway said she would buy the silk herself', 'with the word "silk" crossed out and the word "gloves" written in above it'. He continues: 'Woolf seems to have been testing different words in that slot; it is anyone's guess how much thought she gave to this one revision' (Gaipa, 'Accessorizing Clarissa', 42 n.2).

${ }^{29}$ Mark Spilka, 'On Mrs. Dalloway's Absent Grief: A Psycho-Literary Speculation', Contemporary Literature 20:3 (1979), 316-338 (326); my emphasis. See also Gaipa, 'Accessorizing Clarissa', 24. The word in this sentence that troubles Gaipa the most is neither 'gloves' nor 'flowers' but 'herself', and his article opens up to a rich discussion of Clarissa's need to purchase her own gloves and the implications of this for the 'body double' that will feature in Mrs Dalloway.

${ }^{30}$ Spilka, ‘On Mrs. Dalloway’s Absent Grief', 326.

${ }^{31}$ The representation of flora and fauna in Woolf's work has been frequently discussed by critics such as Elisa Sparks, who argues that flowers have a triple function in Woolf's writing, as 'literal natural organisms, as artificial renderings of the natural, and as figurative strategies'. She notes the 'several thematic trends in Woolf's use of flowers and flower imagery', referencing critics such as Jane Goldman and Bonnie Kime Scott, who discuss the representation of flowers in terms of the unconscious, as lesbian desire, and as a structural device. Elisa K. Sparks, 'Virginia Woolf's Literary and Quotidian Flowers: A Bar-Graphical Approach' in Virginia Woolf and Nature: Proceedings from the Twentieth Annual International Conference on Virginia Woolf, edited by Kristin Czarnecki and Carrie Rohman (Clemson, Clemson University Press, 2011), 42-57 (42).

${ }^{32}$ Bonnie Kime Scott, 'The Word Split Its Husk: Woolf's Double Vision of Modernist Language', Modern Fiction Studies 34:3 (1988), 371-85 (375).

${ }^{33}$ Jacques Derrida, Positions [1972], translated by Alan Bass (London, Continuum, 2004), 41.

${ }^{34}$ Derrida, Positions, 42. 
${ }^{35}$ Gayatri Chakravorty Spivak, 'Translator's Preface' in Jacques Derrida, Of Grammatology [1967]

(Baltimore, Johns Hopkins University Press, 1997), ix-Ixxxvii (Ixv).

${ }^{36}$ Spivak, 'Translator's Preface', xlvi.

${ }^{37}$ Genet, The Maids, 25.

${ }^{38}$ Sussman, 'Hegel, Glas, and the Broader Modernity', 285.

${ }^{39}$ See Naas's forthcoming essay on 'Derrida's Floruit' for a discussion of 'how to think (...) the fl. of gl' in Glas. Michael Naas, 'Derrida's Floruit', Derrida Today (forthcoming, 2016).

${ }^{40}$ Furst, Idioms of Distress, 35.

${ }^{41}$ Furst, Idioms of Distress, 35.

${ }^{42}$ Nicholas Royle, Veering: A Theory of Literature (Edinburgh, Edinburgh University Press, 2011), 152.

${ }^{43}$ Hélène Cixous, Hyperdream [2006], translated by Beverley Bie Brahic (Cambridge, Polity, 2009), 104.

${ }^{44}$ For a discussion of the relationship between inheritance and the hand see Jackson, Tactile Poetics, $145-147$. 